\title{
Short communication \\ Assessment of the pro-inflammatory activity of water sampled from major water treatment facilities in the greater Pretoria region
}

\author{
SA Adebayo', LJ Shai ${ }^{1 *}$, MC Cholo $^{2}$, R Anderson ${ }^{2}$ and D du Toit ${ }^{1}$ \\ 'Dept of Biomedical Sciences, Faculty of Science, Tshwane University of Technology, Private Bag X680, Pretoria 0001, South Africa \\ ${ }^{2}$ Medical Research Council Unit for Inflammation and Immunity, Dept of Immunology, Faculty of Health Sciences, University of Pretoria, \\ and Tshwane Academic Division of the National Health Laboratory Service, Pretoria, 0001, South Africa
}

\begin{abstract}
Notwithstanding direct detection of microbial/viral pathogens or their associated toxins, the quality of drinking water may also be evaluated according to its pro-inflammatory potential. In this latter setting, contamination with pathogens or their products is determined according to the magnitude of activation of blood-derived immune/inflammatory cells following exposure to test water samples in vitro, usually by monitoring the synthesis of pro-inflammatory cytokines. The primary objective of the current study was to apply this procedure to evaluate the pro-inflammatory potential of water sampled at entry, as well as at various stages of treatment, from 3 major water treatment facilities in the greater Pretoria region, viz., the Daspoort, Hartbeespoort, and Rietvlei Water Treatment Facilities. Control water samples included domestic tap water, bottled water from a commercial source, and distilled water. Peripheral blood mononuclear leukocytes (MNL) were isolated from the blood of healthy, adult, human volunteers $(n=3)$, enumerated, suspended in tissue culture medium RPMI 1640 containing antibiotics at a concentration of $1 \times 10^{6} / \mathrm{m} \ell$, and exposed to the various water samples $(10 \%)$ for $18 \mathrm{~h}$ at $37^{\circ} \mathrm{C}$. Following incubation, the cell-free supernatants were assayed for the cytokine, interleukin-6 (IL-6), using a quantitative, sandwich, enzyme immunoassay procedure. The mean values for the untreated control system and for a positive control system exposed to bacterial endotoxin $(120 \mathrm{ng} / \mathrm{m} \ell)$ were $153.5 \pm 17$ and $1561 \pm 30 \mathrm{pg} / \mathrm{m} \ell$, respectively $(p=0.03)$. The production of IL- 6 was unaffected following exposure of MNL to the control water samples. However, inlet water sampled from all three facilities, especially Hartbeespoort, resulted in significant activation of production of IL- 6 by MNL, which declined with progressive treatment, consistent with removal of pro-inflammatory contaminants. Surprisingly, however, a rebound in pro-inflammatory activity was evident in outlet water sampled from Hartbeespoort. In conclusion, the results of the current study appear to support the efficiency of water treatment procedures at the Daspoort and Rietvlei Treatment Facilities, while confirming the usefulness of IL-6-based assays as adjuncts to conventional water quality testing procedures.
\end{abstract}

Keywords: Endotoxin, inflammatory activity, interleukin-6, mononuclear leukocytes, water quality

\section{INTRODUCTION}

Traditional water quality testing techniques test for the presence of indicator organisms (Hunter, 2003). However, certain substances such as endotoxin may still be present in the water, and are rarely detected by traditional methods (Wichmann et al., 2004; Gorbet and Sefton, 2005; Slabbert et al., 2008; Pool, 2008). The inflammatory activity in environmental water samples has been investigated using in vitro human immune response tests, specifically the production of pro-inflammatory cytokines by whole blood or isolated leukocytes (Pool et al., 2003; Wichmann et al., 2004; Pool and Magcwebeba, 2009). In the study reported by Wichmann et al. (2004), exposure to treated drinking water samples did not induce cytokine secretion by human leukocytes in vitro, while contrasting effects were observed following exposure to all the river water samples tested, confirming the findings of an earlier study (Pool et al., 2003). These latter authors reported that induction of secretion of the cytokine, interleukin (IL)-6, was dependent on the concentration of the contaminant(s) and origin of the

To whom all correspondence should be addressed

IIII +2712 382 6342, fax: +27 12382 6262; e-mail: ShaiLJ@tut.ac.za

Received 30 January 2013; accepted in revised form 20 March 2014. water samples. More recently, exposure of whole blood from healthy adult human volunteers to hydrophobic extracts of contaminated surface water samples resulted in the synthesis of pro-inflammatory IL-6, while suppressing biomarkers of both cell-mediated and humoral immunity (Pool and Magcwebeba, 2009). In addition, several reports have documented that treated drinking water samples, sewage effluents entering river water consumed by humans, and river water treated with insecticides, possess pro-inflammatory activities (Pool, 2008; Slabbert et al., 2008; Mompelat et al., 2009). Clearly, difficultto-detect pro-inflammatory substances in water may pose a threat to public health.

With increasing awareness of this threat, the measurement of the pro-inflammatory activity of drinking water from various sources is clearly a useful adjunctive strategy to complement traditional testing procedures, as described in several previous reports alluded to above (Pool et al., 2003; Poole et al., 2003; Wichmann et al., 2004; Pool and Magcwebeba, 2009). Although these procedures have been used to assess the human health-related quality of water from various sources in several provinces in South Africa, they have not, to our knowledge, been used in the comparative analysis of water from major treatment facilities in Gauteng Province. Accordingly, the primary objective of the current study was to assess the proinflammatory activity of water samples from the Daspoort, Hartbeespoort, and Rietvlei treatment facilities, using 
measurement of production of IL- 6 by water-exposed isolated human blood MNL, in vitro, as the biomarker of inflammatory activity.

\section{METHODS}

\section{Preparation of mononuclear leukocytes (MNL)}

Permission to draw blood from healthy, non-smoking adult human volunteers was granted by the Research Ethics Committee of the Faculty of Health Sciences of the University of Pretoria (Protocol number 43/2006, date of renewal: 29 June 2009). Subsequent to a satisfactory health check by a qualified nursing sister and obtaining informed consent, MNL were prepared from heparinised (5 units of preservative-free heparin/ $\mathrm{m} \ell$ ) venous blood from 3 different donors. Following centrifugation of heparinised whole blood on Histopaque-1077 cushions (Sigma-Aldrich, St Louis, MO, USA), the MNL fraction at the plasma/Histopaque-1077 interface was aspirated, diluted $1 / 5$ with phosphate-buffered saline (PBS, $0.15 \mathrm{M}, \mathrm{pH} 7.4$ ) and the cells pelleted by centrifugation, after which contaminating erythrocytes were removed by hypotonic lysis with $0.83 \%$ ammonium chloride. Subsequent to another centrifugation step and discarding of the supernatant fluid, the cells were re-suspended in sterile tissue culture medium RPMI 1640 (Highveld Biological, Johannesburg) containing antibiotics (penicillin: streptomycin: amphotericin B, 0.1: 0.25: $0.1 \mu \mathrm{g} / \mathrm{ml}$ ). The MNL preparation was then analysed flow cytometrically using a Beckman Coulter FC500 Flow Cytometer using the following fluorochrome-labelled monoclonal antibodies (Beckman Coulter, Miami, FL, USA): CD3 (FITC), CD15 (FITC), CD14 (PE), and CD19 (PE) for analysis and enumeration of total $\mathrm{T}$ cells, neutrophils, monocytes and B-cells, respectively. The cell preparations were adjusted to a concentration of $1 \times 10^{7} / \mathrm{m} \ell$ in RPMI 1640 with antibiotics and viability determined flow cytometrically using a propidium iodide dye $(50 \mu \mathrm{g} / \mathrm{m} \ell$, final) exclusion procedure. The cells $\left(2 \times 10^{5} / \mathrm{m} \ell\right)$ were incubated with the dye for $5 \mathrm{~min}$ at $37^{\circ} \mathrm{C}$, analysed flow cytometrically and the results expressed as \% viable cells.

\section{Collection of water samples}

Water samples $(10 \mathrm{~m} \ell)$ were collected between February and April 2010, into sterile universal containers, kept on ice or at $4^{\circ} \mathrm{C}$ during transport to the laboratory, filtered and processed within $24 \mathrm{~h}$ of collection. For the assay of pro-inflammatory activity, water samples were filtered using Whatman filters of pore size $0.22 \mu \mathrm{m}$. Control water samples were collected from: (i) domestic taps (2 sources in Johannesburg and Pretoria); (ii) a commercial source (bottled water); and (iii) distilled water, all of which were presumed to be well treated and potable for domestic and drinking purposes. Environmental water samples were taken from 3 different water treatment facilities in Pretoria and Hartbeespoort, South Africa. The selected facilities included the Hartbeespoort Dam Water Treatment Plant (GPS: $25^{\circ} 43^{\prime} 530^{\prime \prime} \mathrm{S}, 27^{\circ} 50^{\prime} 873^{\prime \prime} \mathrm{E}$ ), the Daspoort Sewage Treatment Plant (GPS: $25^{\circ} 43^{\prime} 16.72^{\prime \prime}$ S, $28^{\circ} 03^{\prime} 14.07^{\prime \prime} \mathrm{E}$ ) and the Rietvlei Dam Water Treatment Facility (GPS: $25^{\circ} 52^{\prime} 34^{\prime \prime}$ S, $28^{\circ} 15^{\prime} 54^{\prime \prime}$ E). Samples were collected at various stages of treatment, from the entry of untreated raw water (inlet water), through the final stages of treatment (outlet), and also at domestic taps supplied by the treatment plants. All samples were treated identically using RPMI 1640 with antibiotics as the diluent.

\section{Interleukin-6 (IL-6) assay}

MNL $\left(1 \times 10^{6}\right)$ suspended in $900 \mu \ell$ RPMI 1640 supplemented with $5 \%$ autologous serum and antibiotics in $5 \mathrm{~m} \ell$ tissue culture tubes were pre-incubated for $15 \mathrm{~min}$ at $37^{\circ} \mathrm{C}$ followed by addition of $100 \mu \ell$ of one of the following to the various control and experimental systems: (i) RPMI 1640 containing antibiotics (negative control system); (ii) bacterial lipopolysaccharide, (Sigma-Aldrich), an activator of IL-6 synthesis, at a final, fixed concentration of $120 \mathrm{ng} / \mathrm{m} \ell$ (positive control system); and (iii) the test water samples, either undiluted, or diluted with RPMI 1640 containing antibiotics. The final volume in each tube was $1 \mathrm{ml}$, and the tubes were then incubated for $18 \mathrm{~h}$ at $37^{\circ} \mathrm{C}$ in an atmosphere of $5 \% \mathrm{CO}_{2}$. Following incubation, the MNL were pelleted by centrifuging the tubes at $1200 \mathrm{r} / \mathrm{min}$ for $10 \mathrm{~min}$ and the cell-free supernatants aspirated into sterile Eppendorf tubes and assayed for extracellular IL- 6 using a commercial quantitative sandwich enzyme immunoassay procedure according to the manufacturer's instructions (Quantikine Human IL-6, R\&D Systems Inc., MN, USA) and the results expressed as $\mathrm{pg} / \mathrm{m} \ell$ supernatant.

\section{Expression and statistical analysis of results}

A total of 3 different experiments using MNL from 3 different donors were performed with triplicate determinations for each system in each experiment. The results are expressed as the mean values \pm standard deviation (SD), while statistical analyses were performed using GraphPad Instat version 3. The probability value $(p)$ was calculated using a non-parametric unpaired, two-tailed Mann-Whitney test.

\section{RESULTS}

\section{Cellular composition of MNL suspensions}

The mean numbers ( \pm SDs) of leukocyte subsets in the MNL suspensions from the 3 different donors were as follows: 54.4 $\pm 9.1 \%$ T cells, $15.7 \pm 6.3 \%$ B cells, $10.8 \pm 6.6 \%$ monocytes and $2.1 \pm 1.3 \%$ contaminating neutrophils. The balance is likely to consist of natural killer cells and other leukocyte subtypes represented at low concentrations in blood. The mean percentage MNL viability was $97.5 \pm 0.4 \%(n=3)$.

\section{Effect of exposure of MNL to control water samples on IL-6 production}

These results are shown in Fig. 1 which, relative to the negative control system, demonstrates a clear lack of effect of exposure of MNL to the various control water samples on IL-6 production. In the case of the positive control system, exposure of the cells to bacterial endotoxin resulted in a statistically significant ( $p=0.03)$, substantial increase in synthesis of IL-6.

\section{Effect of exposure of MNL to environmental water samples on IL- 6 production}

These results, which are shown in Fig. 2, demonstrate that several of the water samples tested induced statistically significant $(p<0.0001)$ induction of synthesis of IL- 6 by exposed MNL compared with the negative control systems, though the degree to which this occured varied according to the origins of the samples. Those which were most potent with respect to induction of IL-6 synthesis originated from the inlet source at the 


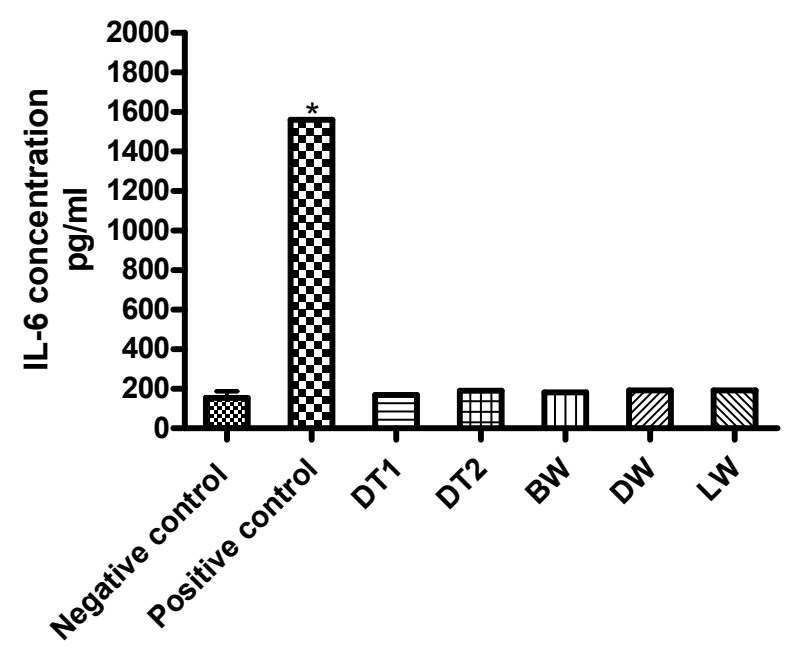

Control water samples

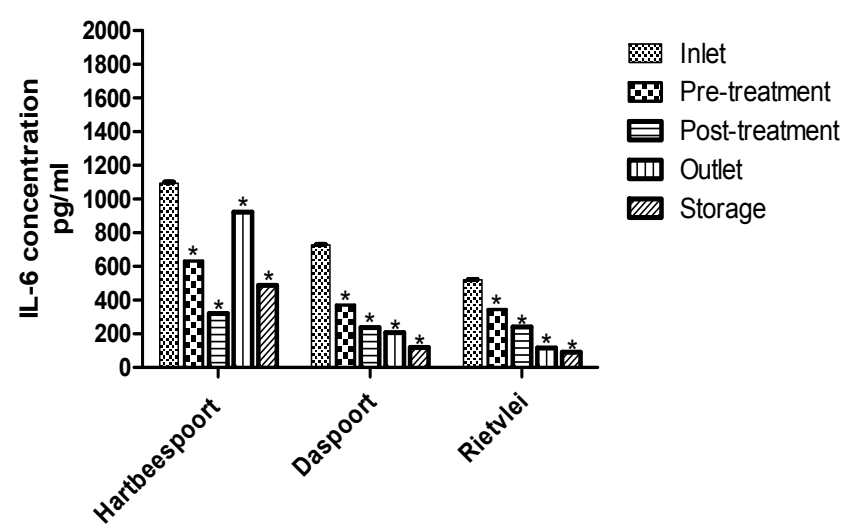

Water treatment facility

Hartbeespoort Dam Water Treatment Facility, reaching a maximum value of $1094 \mathrm{pg} / \mathrm{m} \ell$, considerably higher than the value of the corresponding negative control system. Although lower than the Hartbeespoort value, the inlet water samples from the Daspoort treatment facility also induced significant induction of IL-6 ( $p=0.0001$ ) when added to MNL. In all cases, successive treatments resulted in progressive loss of pro-inflammatory activity, which in the case of the Daspoort and Rietvlei facilities was essentially complete at the post/outlet/storage points. Surprisingly, however, despite statistically significant decreases at the pre/post treatment phase, a rebound in pro-inflammatory activity was detected in outlet water from the Hartbeespoort Treatment Facility $(p<0.0001)$.

\section{Effects of dilution on the pro-inflammatory activity of inlet and outlet water from the Hartbeespoort Dam Water Treatment Plant}

Inlet water samples from the Hartbeespoort Dam Water Facility were very turbid. Accordingly, dilutions of $1 / 10$ and $1 / 100$ in RPMI 1640 with antibiotics were made of both inlet and outlet water samples after filtration to assess potency with respect to induction of IL- 6 production by MNL. These results, which are shown in Fig. 3, demonstrate no loss of pro-inflammatory potency of inlet water following dilution of $1 / 10$ ( $p=$ 0.9045), while there is clear loss of pro-inflammatory potency of outlet water at a dilution of $1 / 10(p=0.0007)$.
Figure 1(left)

Effects of exposure of MNLs to: (i) RPMI 1640 with antibiotics (negative control); (ii) bacterial endotoxin (120 ng/m $\mathrm{m}$, positive control); (iii) DT1 (domestic tap water, Johannesburg); (iv) DT2 (domestic tap water, Pretoria); (v) BW (commercially bottled water); (vi) DW (distilled water); and (vii) LW (laboratory tap water). The results of 3 separate experiments using MNL from 3 different donors are expressed as the mean values \pm SDs with triplicate determinations for each system in each experiment.

*The value for the positive control system was significantly higher $(p<0.03)$ than those for the negative control system and the various water sources, which did not differ significantly from one another.

\section{Figure 2 (left)}

Comparison of the effects of water sampled from the 3 different treatment facilities, before, during and after treatment, on the production of IL- 6 by isolated human MNLs. The results of 3 separate experiments using MNL from 3 different donors are expressed as the mean values $\pm S D$ s with triplicate determinations for each system in each experiment. In all cases, the pre-treatment, post-treatment, outlet and storage values were significantly lower ( $p<0.0001)$ than those of the corresponding inlet values for each water treatment facility.

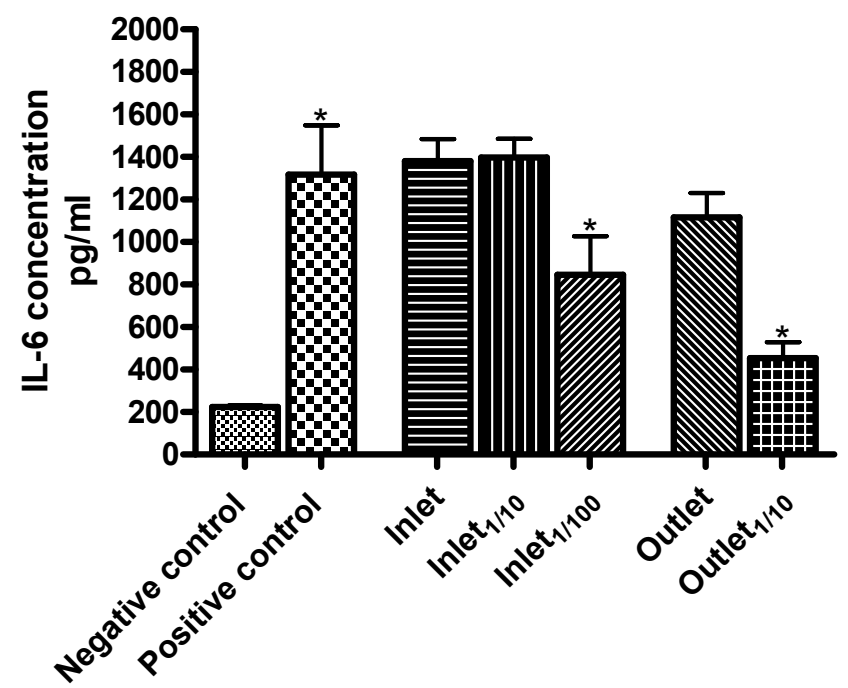

Hartbeespoort dam samples

Figure 3

Effects of dilution $(1 / 10$ and/or $1 / 100)$ of inlet and outlet water sampled from the Hartbeespoort Water Treatment Facility on the production of IL- 6 by isolated human MNLs. The results of 3 experiments using cells from 3 different donors are expressed as the mean values \pm SDs with triplicate determinations for each system in each experiment. The positive and negative control systems contained bacterial endotoxin $(120 \mathrm{ng} / \mathrm{ml})$ and an equivalent volume of RPMI 1640 containing antibiotics, respectively; ${ }^{*} p<0.0001$ for comparison with the corresponding undiluted systems. 


\section{DISCUSSION}

Various water contaminants, including bacteria, viruses and their breakdown products, have been shown to cause adverse health effects in humans, which are characterised by fever, diarrhoea, and, in extreme cases, anaphylactic shock (Emmanuel et al., 2007). Traditional water treatment procedures such as chlorination are designed to eliminate living organisms, but chlorination has little or no effects on bacterial breakdown products such as endotoxin (Gorbet and Sefton, 2005). Although some assays such as the limulus amoebocyte lysate (LAL) test detect microbial breakdown products such as Gram-negative bacterial endotoxin, which may be present in river and drinking water (Poole et al., 2003; Wichmann et al., 2004; Gorbet and Sefton, 2005; Pool, 2008), these procedures are ineffective in the detection of other pyrogenic substances (Gorbet and Sefton, 2005; Hodgson, 2006).

Alternative assays include assessment of the inflammatory activity of water as an indirect index of quality. In this setting, measurement of the cytokine IL-6, following exposure of whole blood or isolated leukocytes to test water samples in vitro, is a useful strategy to detect inflammatory activity (Wichmann et al., 2004; Pool and Magcwebeba, 2009). This procedure was used in the current study to determine the quality of water sampled at various stages prior to, during, and following the treatment process at 3 water treatment facilities in the greater Pretoria region, relative to that of control water samples.

The results revealed that none of the control water samples tested affected the production of IL- 6 by MNL isolated from the blood of 3 healthy adult human volunteers, the levels of production of the cytokine being comparable with those of the negative control systems. In the case of the water treatment facilities (Daspoort, Hartbeespoort and Rietvlei), however, inlet water from all three, especially Hartbeespoort, was found, not unexpectedly, to possess significant inflammatory activity. The purification procedures in all three treatment facilities were associated with a progressive loss of pro-inflammatory activity, with the values for outlet and storage water sampled from the Daspoort and Rietvlei facilities being equivalent to or lower than that of the negative control system.

Surprisingly, however, a rebound in pro-inflammatory activity was detected in the outlet water, in particular, and, to a lesser extent, the storage water, sampled from the Hartbeespoort facility. We are not aware of previous studies which have investigated the inflammatory potential of Hartbeespoort Dam water. Although the possible health hazards of consumption of water with residual inflammatory activity are unknown, our findings are consistent with reports of poor water quality, with users often complaining of the unpleasant odour of treated water which originated from the Hartbeespoort Dam Water Treatment Facility (Dower, 2005; Venter, 2005; DWAF, 2008). Hartbeespoort Dam is well-known for its algae blooms (blue-green algae), especially cyanobacteria species and their microcystin toxins, as well as other bacteria known to produce toxins (Venter, 2005; DWAF, 2008). Although many of these toxins are heat-resistant and not affected by filtration and chlorination (Gorbet and Sefton, 2005), the progressive loss of inflammatory activity appears to exclude inefficiency of the treatment processes as the reason for the unexpectedly high level of inflammatory activity in the outlet and storage water. Alternative possibilities include equipment failures, re-contamination, improper disinfection processes, and inadequate removal of disinfectants, poor storage practices, inadequate or unskilled manpower or a combination of these factors, which might have contributed to the inflammatory reactivity of the outlet water at the time of sampling. Determining the actual factors responsible for the inflammatory reactivity in the water samples was, however, outside the scope of the present study.

In the case of the Daspoort Sewage Treatment Facility, the inlet water consists of sewage and waste water effluents from Pretoria, presumably rich in biological wastes with a high concentration of bacteria, e.g., coliforms and E. coli. This probably explains the relatively high inflammatory reactivity seen at the inlet point, which decreased progressively as the water passed through the treatment processes. The operating principles of the Daspoort Waste Water Treatment Works, incorporating the external nitrification biological nutrient removal activated sludge system for increased efficiency, have been described in detail by Muller et al. (2004). The treated water pumped to the hydro-powered station and back into the Apies River (storage water for Daspoort Dam Water Treatment Plant) was not potentially harmful, which is in agreement with the report by Muller et al. (2004), and is important for the maintenance of biodiversity in the aquatic environment. The Apies River water flows down to the Delmas Water Treatment Facility to be treated for domestic use.

Although the Rietvlei Dam flows through industrial and residential areas (City of Tshwane, 2003), the results showed that it is the least polluted water of the environmental water samples tested in this study. This may be attributed to the fact that water flowing into the dam is derived from 4 natural springs and very few effluents are discharged into the dam (City of Tshwane, 2003). Although occasional filter blockages have been reported at the Rietvlei Dam Water Treatment Plant due to abnormal algal blooms in the upper layer of Rietvlei Dam, especially during winter (Rietvlei Dam, 2009), reports of poor water quality are very rare. These algae species are effectively removed from the water by pre-chlorination and backwashing at more regular intervals (City of Tshwane, 2009). In addition, a wetland occurs upstream of the Rietvlei Dam which slows down water flow, causing suspended matter to settle out. The Rietvlei Dam Water Treatment Plant supplies 5\% of the domestic and industrial water needs of the Tshwane Municipality, and reports of poor water quality or taste are rare (City of Tshwane, 2003).

We do concede that the current study suffers from several limitations, including the relatively small number of blood donors $(n=3)$ and lack of serial sampling over an extended period. Nevertheless, the results of this pilot study appear to identify varying efficiencies of the water treatment practices at three major treatment facilities in the greater Pretoria region, while confirming the usefulness of testing for inflammatory potential as an adjunct to traditional water testing procedures.

\section{REFERENCES}

CITY OF TSHWANE (2003) Rietvlei Nature Reserve - historical background. Water and Sanitation Division, City of Tshwane, Pretoria.

CITY OF TSHWANE (2009) Pre-chlorination at Tshwane Municipality. Rietvlei Dam Water Treatment Works. City of Tshwane, Pretoria.

DWAF (DEPARTMENT OF WATER AFFAIRS AND FORESTRY, SOUTH AFRICA) (2008) Hartbeespoort Dam integrated biological remediation programme. DWAF Resource Management Plan. Workshop, June 2008. Department of Water Affairs and Forestry, Pretoria. 
EMMANUEL E, ANGERVILLE R, JOSEPH O and PERRODIN Y (2007) Human health risk assessment of lead in drinking water: a case study from Port-au-Prince, Haiti. Int. J. Environ. Pollut. 31 (3-4) 280-291.

GORBET MB and SEFTON MV (2005) Endotoxin: the uninvited guest. Biomaterials 26 (34) 6811-6817.

HUNTER RP (2003) Drinking water and diarrhoeal disease due to Escherichia coli. J. Water Health 1 (2) 65-72.

MOMPELAT S, LE BOT B and THOMAS O (2009) Occurrence and fate of pharmaceutical products and by-products, from resource to drinking water. Environ. Int. 35 (5) 803-814.

MULLER AW, WENTZEL MC, SAAYMAN GB, VAN DER MERWE SA, ESTERHUYSE CM, SNYMAN JS and EKAMA GA (2004) Full-scale implementation of external nitrification biological nutrient removal at the Daspoort Waste Water Treatment Works. Water SA 30 (5) 37-48.

POOL EJ (2008) The estrogenicity of sewage effluent entering the Eerste-Kuils River catchment system. WRC Report No. 1590/1/08. Water Research Commission, Pretoria.

POOL EJ and MAGCWEBEBA TU (2009) The screening of river water for immunotoxicity using an in vitro whole blood culture assay. Water Air Soil Pollut. 200 25-31.
POOL EJ, JAGALS C, VAN WYK JH and JAGALS P (2003) The use of IL-6 induction as a human biomarker for inflammatory agents in water. Water Sci. Technol. 47 (3) 71-75.

POOLE S, MISTRY Y, BALL C, GAINES DAS RE, OPIE LP, TUCKER $\mathrm{G}$ and PATEL M (2003) A rapid 'one plate' in vitro test for pyrogens. J. Immunol. Meth. 274 (1-2) 209-220.

SLABBERT JL, VENTER EA, MOLETSANE M, VAN WYK JH, BLAISE C and ANECK-HAHN N (2008) An investigation of the estrogenic activity in water from selected drinking water treatment processes. WRC Report No. 1532/1/08. Water Research Commission, Pretoria.

VENTER P (2005) North West Environmental Management Series 5. Dam Remediation, Hartbeespoort Dam. Doc. F0034. North West Provincial Government, Mafikeng, South Africa.

DOWER S (2005) Water quality: would you swim here? The Water Wheel 4 (1) 16-20.

WICHMANN G, DAEGELMANN C, HERBARTH O, STRAUCH G, SCHIRMER K, WöSTEMEYER J and LEHMANN I (2004) Inflammatory activity in river-water samples. Environ. Toxicol. 19 (6) 594-602. 
http://dx.doi.org/10.4314/wsa.v40i2.20 Available on website http://www.wrc.org.za

ISSN 0378-4738 (Print) = Water SA Vol. 40 No. 2 April 2014 ISSN 1816-7950 (On-line) = Water SA Vol. 40 No. 2 April 2014 